\title{
O DÉFICIT DEMOCRÁTICO DA REGULAÇÃO NOS MECANISMOS DE GESTÃO COMPARTILHADA DA POLÍTICA NACIONAL DE RECURSOS HÍDRICOS BRASILEIRA
}

\author{
THE DEMOCRATIC DEFICIT OF REGULATION IN THE SHARED \\ MANAGEMENT MECHANISMS OF THE BRAZILIAN NATIONAL \\ WATER RESOURCES POLICY
}

André Augusto Giuriatto Ferraço ${ }^{1}$

$\mathrm{UnB}$

\begin{abstract}
Resumo:
O artigo investiga a existência de um suposto déficit democrático nos instrumentos de participação do setor hídrico, a partir da análise dos Comitês de Bacia Hidrográfica como mecanismos idealizados pela Política Nacional de Recursos Hídricos para assegurar a participação e a gestão compartilhada dos recursos hídricos. A pesquisa se utiliza da revisão bibliográfica e do estudo de casos amostrais, de modo exemplificativo, em situações de conflito de interesses, para analisar a gestão compartilhada do recurso desde os Comitês de Bacia Hidrográfica até a agência reguladora. Utiliza-se como marco teórico o estudo de Marçal Justen Filho sobre o déficit democrático da regulação no contexto da regulação publicamente interessada, a partir do qual se propõe a sistematização de critérios analíticos para a verificabilidade do referido déficit. Com base no método indutivo, defende-se que o déficit democrático externo na regulação hídrica é suprido pela atuação dos entes que compõem o Sistema Nacional de Gerenciamento de Recursos Hídricos, em especial pela atuação da Agência Nacional de Águas e pelos Comitês de Bacia Hidrográfica. Quanto ao déficit democrático interno, o estudo dos casos exploratório demonstra que, em determinadas situações, pode haver um descompasso entre os interesses dos entes do referido sistema, o que conduz a uma fragmentação da bacia hidrográfica em razão de interesses sobrepostos, ocasião em que se verifica a prevalência da legitimação democrática pelo procedimento.

Palavras-chave:

Déficit democrático, setor hídrico brasileiro, Comitês de Bacia Hidrográfica, mecanismos de participação, procedimento administrativo.
\end{abstract}

\begin{abstract}
:
The article investigates the existence of a democratic deficit in the instruments of participation in the water sector, based on the analysis of the River Basin Committees as mechanisms idealized by the National Water Resources Policy to ensure the participation and shared management of water resources. The research uses the bibliographic review and the study of sample cases, in an exemplary way, in situations of conflict of interest, to analyze the shared management of the resource from the Hydrographic Basin Committees to the Water Regulatory Agency. The theoretical framework of Marçal Justen Filho's study on the democratic deficit of regulation in the context of publicly interesting regulation is used as the basis for proposing the systematization of analytical criteria for the verification of said deficit. Based on the inductive method, the research findings demonstrate that the external democratic deficit in water regulation is supplied by the actions of the entities from the National Water Resources Management System, particularly by the actions of the National Water Agency and the Watershed Committees. As for the internal democratic deficit, the case study shows that, in certain situations, there may be a mismatch between the interests of the national system members, which leads to a fragmentation of the river basin due to overlapping interests, when the prevalence of the democratic legitimation by the procedure becomes notorious.
\end{abstract}

Keywords:

Democratic deficit, Brazilian water sector, river basin committees, participation mechanisms, administrative procedure.

\section{INTRODUÇÃO}

O Estado Regulador tem por pressuposto a proteção dos direitos fundamentais, de modo

\footnotetext{
${ }^{1}$ Doutorando e mestre em Direito, Estado e Constituição pela Universidade de Brasília - UnB. Professor voluntário de Direito dos Desastres Ambientais na Universidade de Brasília - UnB. Pesquisador institucional do Instituto Brasiliense de Direito Público - IDP.
} 
que a intervenção dirigente e gerencial da Administração Pública deve garantir as prestações materiais essenciais à fruição desses direitos. No contexto da regulação hídrica, um importante mecanismo para assegurar o exercício de direitos fundamentais dos particulares são os Comitês de Bacia Hidrográfica $(\mathrm{CBH})$, entes que garantem a efetivação do direito à participação e gestão compartilhada dos recursos hídricos. Uma vez que a efetivação dos direitos fundamentais está conectada à noção de Estado Democrático de Direito, torna-se relevante analisar em que medida a atuação das agências reguladoras cumpre o papel de intermediar a participação direta do cidadão na formação da vontade política para a concretização destes direitos.

Não há um vínculo democrático direto, caracterizado pelo sufrágio, entre a população e as agências reguladoras independentes. Em regra, a criação das agências e a escolha dos seus dirigentes não ocorrem a partir da manifestação da vontade da maioria populacional. Dessa forma, pode-se questionar se a estrutura regulatória carece de legitimidade democrática em sua formação, estrutura e função, elementos que, em última análise, podem colocar em risco as garantias fundamentais.

Não obstante, a busca por mecanismos de mediação entre as estruturas reguladoras e os particulares é uma constante no atual Estado Regulador. No âmbito da regulação hídrica, esse déficit democrático é minorado por meio da atuação dos Comitês de Bacia Hidrográfica, idealizados pela Política Nacional de Recursos Hídricos (PNRH) como um instrumento de democracia participativa, no qual a sociedade civil assume maior relevância no momento de tomada de decisões.

Os Comitês de Bacia Hidrográfica são um importante mecanismo de abertura democrática da regulação hídrica, tendo como objetivo viabilizar a participação para a gestão compartilhada do recurso. Nos moldes da estrutura proposta pela PNRH, objeto deste estudo, a criação dos Comitês de Bacia Hidrográfica teve a finalidade de institucionalizar a descentralização da administração do recurso, conforme o fundamento da lei das águas (art. $1^{\circ}$, inciso IV, da PNRH). Na origem desses instrumentos, tem-se uma abertura participativa e consensual para a manifestação de múltiplos interesses públicos e privados em torno dos usos comuns dos recursos hídricos, as quais, quando incorporadas aos planos, delimitam as diretrizes para a aplicação dos demais instrumentos previstos pela PNRH em uma bacia hidrográfica.

O recorte metodológico voltado à análise dos Comitês de Bacia Hidrográfica se deve a dois aspectos principais, intimamente relacionados aos conflitos hídricos nacionais: a ausência da instalação dos comitês em importantes bacias hidrográficas nacionais e à função do comitê como âmbito participativo para resolução de questões controvertidas em unidades de gestão. O primeiro aspecto é um dos principais fatores de conflito nas bacias hidrográficas da região amazônica, ao passo que a ausência de instauração de CBH's obsta a exploração do potencial energético dos 
recursos, uma vez que o comitê é o responsável pela edição dos Planos de Bacia Hidrográfica que definem as diretrizes de outorga e os usos prioritários da água. A importância da análise do segundo aspecto deve-se ao fato de que o $\mathrm{CBH}$ também é um espaço para a resolução de conflitos a partir de perspectiva da região diretamente afetada, na medida em que possibilita a participação democrática dos interessados na gestão do recurso.

Diante desse contexto, questiona-se se a atuação funcional dos Comitês de Bacia Hidrográfica, como mecanismos de gestão democrática e compartilhada dos recursos, tem cumprido seu papel de minorar o déficit democrático na regulação hídrica. Nesse sentido, a problemática que orienta a pesquisa realizada neste artigo se volta para a verificação do alcance democrático dos Comitês de Bacia Hidrográfica como mecanismos de participação democrática e de gestão compartilhada dos recursos hídricos.

Para tanto, a pesquisa se utiliza do método indutivo, amparado pela revisão bibliográfica e a análise exploratória de casos de conflitos hídricos de modo amostral. A partir dessa amostragem exemplificativa, a análise das funções dos comitês realizada neste estudo se direciona dois aspectos centrais da questão hídrica: a exploração do potencial hídrico, no caso das bacias hidrográficas Amazônica e do Tocantins Araguaia, e o grau de envolvimento das instituições públicas do executivo e do judiciário, no caso da bacia hidrográfica do Rio Paraíba do Sul.

O percurso de investigação, quanto ao aspecto democrático dos Comitês de Bacia Hidrográfica, é amparado pelas contribuições de Marçal Justen Filho, publicadas em 2006, no texto “Agências reguladoras e democracia: existe um déficit democrático na Regulação Independente", ao abordar a questão do déficit democrático na regulação independente. Diante da relação entre os direitos fundamentais e a democracia no contexto regulatório, o autor fornece elementos que permitem analisar o índice democrático da regulação independente. Essa proposta teórica tem como hipótese a necessidade de que a atuação das agências deva observar os parâmetros democráticos mínimos, de modo que o referido déficit seria verificado diante da insuficiência de participação popular na atuação das agências.

Nesses moldes, a pesquisa é amparada pela Teoria Processual Administrativa da regulação, uma vez que essa teoria propõe uma regulação direcionada ao interesse público a partir da transparência, participação e controle democráticos no processo de tomada decisória no âmbito regulatório (public interested regulation) ${ }^{2}$. Essa teoria fornece substrato para investigar a eficiência dos instrumentos utilizados para a alocação dos recursos hídricos, bem como para a organização administrativa, em perspectiva com o interesse público consubstanciado na participação pública no

\footnotetext{
2 A Teoria Processual Administrativa da Regulação possui como principal precursor Steven Croley, tendo como objeto de análise o benefício social das manifestações do poder administrativo por meio de seus procedimentos (CROLEY, 1998, 2000 e 2008).
} 
processo de tomada de decisão hídrica, que se mostra essencial para assegurar o direito fundamental à sadia qualidade de vida.

Diante disso, na primeira parte do artigo, serão apresentados os elementos que permitem entender e aferir o índice democrático no modelo regulatório independente (1). Para tanto, num primeiro momento, torna-se necessário caracterizar a existência da eventual tensão entre o modelo regulatório independente a ideia de democracia (1.1) para, em seguida, apresentar os elementos que possibilitam verificar o déficit democrático interno da regulação independente tanto por um prisma estrutural, quanto pelo prisma funcional (1.2).

A partir dos elementos conceituais de análise, a segunda parte do artigo pretende investigar o alcance democrático dos Comitês de Bacia Hidrográfica como mecanismos de participação democrática e de gestão compartilhada dos recursos hídricos (2). Nesse ínterim, a partir da análise do prisma funcional do déficit democrático, verifica-se o índice democrático dos Comitês de Bacia Hidrográfica em suas principais funções: a de instancia administrativa para a resolução de conflitos (2.1) e na elaboração de planos de bacia da unidade de gestão (2.2). Por fim, apresentam-se algumas considerações quanto ao índice democrático da atuação dos $\mathrm{CBH}$ 's como instrumentos de participação democrática no contexto da regulação hídrica (2.3).

\section{A QUESTÃO DO ÍNDICE DEMOCRÁTICO NO MODELO REGULATÓRIO DE AGÊNCIAS INDEPENDENTES}

A atividade normativa, as ações governamentais e as políticas públicas devem atender aos comandos da cidadania, da dignidade da pessoa humana, aos valores sociais do trabalho e da livre iniciativa e ao pluralismo político. Esse conteúdo esculpe os mandamentos do Estado Democrático de Direito no Brasil, no art. $1^{\circ}$ da Constituição Federal Brasileira.

Não obstante, o Estado Democrático de Direito não se manifesta apenas pelo aspecto normativo. Para assegurar o elemento democrático de um estado de direito é necessário que se assegure mecanismos de representatividade social, por meio de instrumentos legítimos e democráticos, que sejam acessíveis, abertos e participativos.

Quanto à concepção de democracia, Marçal Justen Filho tece algumas considerações que merecem destaque e são igualmente adotadas na análise do déficit na regulação realizada neste artigo. Para o autor, a democracia consiste numa experiência concreta, com formulações teóricas e abstratas, de modo que não seria cabível eleger uma determinada concepção teórica como paradigma para avaliação do cunho democrático de um sistema. A análise da democracia deve ser situada temporalmente, não sendo viável subordinar a avaliação do cunho democrático de uma 
organização política atual aos parâmetros de um momento histórico não mais existente. Por fim, a democracia deve ser examinada em face das circunstâncias sócio-políticas do contexto em que é analisada, não sendo viável analisar de modo comparativo padrões institucionais de sociedades diversas, ainda que contemporâneas (JUSTEN FILHO, 2006).

No que se refere à transferência da função normativa de ordem executiva, como verificado no caso das agências independentes, deve-se dispender especial atenção na verificação desse aspecto democrático. Essa medida ganha importância a partir da necessidade de coibir o abuso e a influência de diferentes esferas de poder, bem como de garantir o exercício de direitos fundamentais dos particulares e as prestações estatais positivas.

O equilíbrio democrático pretendido pelo alargamento do poder executivo, por uma perspectiva jurídica, é disciplinado pelo Direito. Nesse sentido, quando há o fortalecimento dos mecanismos de participação e controle, tanto políticos quanto jurídicos, a atividade normativa extraordinária do Poder Executivo encontra compatibilidade com o Estado Democrático de Direito (FIGUEIREDO, 2005).

Nesse contexto, a independência de que gozam as agências reguladoras atenderá aos fins para que foram instituídas quando a sua atuação atender aos princípios da Administração Pública e às diretrizes do Estado Democrático de Direito. Caso contrário, será perceptível a ausência de índices democráticos na regulação independente.

Analisar a existência de um suposto déficit democrático na regulação pressupõe identificar quais são os critérios para a aferição da democracia no modelo regulatório. A fim de que essa análise seja viabilizada, num primeiro momento, (1.1) serão analisados os elementos que demonstram a existência de uma tensão entre o modelo regulatório independente e a democracia para, em seguida, (1.2) apresentar uma proposta analítica de critérios para a verificação da expressão democrática na regulação.

\subsection{A tensão entre o modelo regulatório independente e a democracia}

O questionamento da legitimidade democrática das agências reguladoras independentes deve-se ao fato de que os atos de caráter normativo que emanam dessas instituições não são editados por representantes elegidos pelos cidadãos, mas sim por indicados pelo chefe do poder executivo e aprovados pelo legislativo (DANTAS; GOMES, 2019 e SUNDFELD, 2002, p. 25) cuja legitimidade democrática não se transfere aos reguladores autônomos (BINENBOJM, 2006). Não obstante, uma das principais características da regulação brasileira é a busca por mecanismos participativos que suprem a carência da legitimação democrática em sua atuação (ARAGÃO, 2005). 
Nesse sentido, a atuação das agências reguladoras deve viabilizar a participação dos regulados por meio de instrumentos democráticos. A existência de um déficit democrático é condicionada, portanto, à ausência de mecanismos de participação direta do cidadão na formação da vontade política e à inaplicação das concepções clássicas de tripartição de poderes (JUSTEN FILHO, 2006).

A tensão entre o modelo regulatório independente e a democracia reside no fato de que a legitimação dos diretores e da regulação dispendida por determinado setor não passam pelo crivo eleitoral e, de certo modo, nem deveria. Caso a eleição dos dirigentes estivesse atrelada ao sufrágio, a intervenção estatal seria fortemente influenciada pela barganha dos interesses dos regulados, prejudicando que a tomada de decisão ocorra por um viés mais técnico do que político (RUAS, 2019). Nesse ínterim, a ausência de um procedimento de escolha popular é suprida pela racionalidade econômica e a consecução de interesses públicos na tomada de decisão (MOURA; NETO, 2017), o que não necessariamente reflete os interesses da maioria.

Ainda que a concepção clássica de democracia esteja atrelada ao princípio da eletividade, este não é o único elemento capaz de sustentar a sua existência. A preponderância ilimitada da vontade da maioria não configura, por si só, um regime democrático, uma vez que esta vontade majoritária não pode conduzir à violação de direitos e garantias fundamentais, reconhecidos em prol da totalidade dos cidadãos (JUSTEN FILHO, 2006).

Nesse contexto, um governante eleito pelo povo que, no desempenho de suas funções, desrespeite as instituições fundamentais da Democracia carece de legitimidade democrática. Desse modo, não há que se falar em déficit democrático em razão da ausência de participação direta do povo quando a função institucional consista, precisamente, em neutralizar a influência majoritária e assegurar a realização dos valores e princípios fundamentais (JUSTEN FILHO, 2006).

A partir da compreensão de que o caráter democrático de uma agência é extraído a partir do aspecto técnico de sua atuação, resguardado pela eficiência da regulação, é possível se afirmar que a legitimação democrática das agências reguladoras é amparada pela legitimação técnica, aferida em seu modus operandi (ARANHA, 2019, p. 17-20). A legitimação técnica é mensurada a partir de parâmetros técnico-científicos, os quais se sujeitam aos princípios constitucionais, a exemplo do artigo, $1^{\circ}$, caput, da Constituição Federal, e à finalidade pública em sua execução (MARQUES, 2005).

A legitimação democrática regulatória exige, portanto, uma via alternativa à eletividade. A legitimação técnica das agências reguladoras corrobora para o funcionamento do sistema de freios e contrapesos, assim como amplia as vias de participação entre a sociedade e as instituições públicas. A partir dessa função, o Estado Regulador reposiciona a questão de legitimidade 
democrática por meio da participação do regulado na decisão política ou como espaço de institucionalização da virtude política e do republicanismo (ARANHA, 2019, p.19-20).

Nesse contexto, Justen Filho (2006) ressalta que a existência das agências reguladoras aperfeiçoa o sistema democrático a partir de duas contribuições principais. A primeira, de resguardar a realização de direitos fundamentais, a partir da sua atuação contramajoritária, e a segunda, de ampliar os canais de comunicação entre a sociedade e o Estado, de modo a viabilizar a participação popular na formação de decisões relevantes. Por essa perspectiva, a simples existência das agências reguladoras supre o que o autor denomina de déficit democrático externo, na medida em que atenuam a concentração de poder.

Ainda que a existência de um eventual déficit democrático não possa ser afirmada pela simples inexistência de um procedimento eletivo para a escolha de seus dirigentes, certo é que o índice democrático dessas instituições também não pode ser garantido pelo seu mero estabelecimento. Nesse sentido, torna-se necessário verificar se a estrutura organizacional e a função desempenhada pela agência propiciam a evolução democrática e o aperfeiçoamento da organização estatal, elementos esses que compõem a análise do déficit democrático interno (JUSTEN FILHO, 2006).

A verificação do déficit democrático interno ocorre, portanto, pela análise das funções e estruturas, de modo a evidenciar se a atuação da agencia é pautada pela garantia do exercício de direitos fundamentais, sobretudo, dando abertura à participação popular processo de tomada de decisões. Diante dessa constatação, útil se faz a proposta de um modelo analítico para a verificação de um suposto déficit democrático aplicado à regulação.

\subsection{Uma proposta analítica para a verificabilidade do déficit democrático interno da regulação independente}

O conceito de déficit democrático interno é resultante de características estruturais e funcionais (JUSTEN FILHO, 2006). A análise do déficit democrático a partir de fatores internos possibilita verificar, através da dimensão substantiva da regulação (ARANHA, 2019, p. 42), como se manifestam os fatores democráticos atinentes a determinada agência. A importância dessa análise ganha destaque diante da possibilidade de se falar, de modo incorreto, na superação do referido déficit apenas pela criação de agências ou estruturas regulatórias com o objetivo de viabilizar manifestações democráticas por um viés meramente instrumental, mas que, de fato, não apresentam contribuições substanciais para o aperfeiçoamento do sistema democrático.

Nesse contexto, torna-se necessário que a racionalidade do Estado Regulador passe de uma 
racionalidade material instrumental para uma racionalidade material reflexiva, que possibilite a construção cooperativa de soluções capazes de comunicar os códigos normativos próprios aos sistemas regulado e regulador para a proteção de direitos fundamentais. A partir de uma racionalidade reflexiva, verifica-se um processo de contínuo realinhamento entre os interesses do Estado e dos particulares, em que a regulação estatal conversa com os códigos do sistema regulado e se legitima pelo provimento de serviços essenciais (ARANHA, 2019, p.88-89).

A fim de tornar possível a análise do déficit democrático interno das agências reguladoras, a sistematização de parâmetros analíticos a partir das contribuições de Marçal Justen Filho se apresenta como uma abordagem útil ao tema. Nesse sentido, a análise do déficit democrático interno pode ser orientada a partir de duas perspectivas: uma pautada em elementos estruturais e outra em elementos funcionais que caracterizam o déficit.

Os elementos estruturais caracterizadores do déficit democrático interno relacionam-se à organização da entidade reguladora (JUSTEN FILHO, 2006, p. 310-316). Esses elementos podem ser organizados em quatro grupos principais, que dizem respeito à (I) composição colegiada com competências compartilhadas, (II) à disciplina sobre a escolha dos membros, (III) à disciplina sobre a situação jurídica dos dirigentes das agências e (IV) à disciplina sobre a competência regulatória.

A pluralidade da composição da agência com competência compartilhada entre os colegiados é um importante elemento de democratização (I). A partir dessa configuração, há uma dissolução da concentração de poder, de modo a reduzir a ocorrência de eventuais influências subjetivas no processo decisório. Ainda que a tomada de decisão individual possa contemplar várias visões subjetivas, o modelo pluripessoal apresenta maior intensidade democrática do que uma concepção única, na medida em que as competências compartilhadas originam manifestações de vontade conjunta.

No que se refere à escolha dos membros (II), o sistema de seleção não deve conduzir à admissão de qualquer solução para investidura no cargo de direção da agência. As competências decisórias para a nomeação dos membros devem ser fracionadas, a fim de que se evite abuso de poder, interferências políticas ou escolhas de índole pessoal do chefe do executivo. É fundamental que a direção da agência seja imparcial, tanto por um viés político quanto econômico, e que a sua composição reforce os instrumentos de freios e contrapesos internos.

Outro importante fator que diz respeito à disciplina de escolha dos dirigentes é de que os mandatos sejam descoincidentes, a fim de que haja uma pluralidade de representantes escolhidos e indicados por diferentes governantes e aprovados por diferentes partidos. Com isso, o processo decisório contempla diferentes vertentes políticas, evitando a preponderância da orientação política prevalente em outras instituições públicas. Além disso, a blindagem política na investidura dos 
dirigentes deve observar a capacitação técnico-científica dos indicados a partir de requisitos objetivos, que reforçam a racionalidade técnica almejada pelas agências reguladoras.

No que tange à situação jurídica dos dirigentes das agências (III), esta deve propiciar a independência do agente público no processo decisório. Para tanto, deve ser assegurada a garantia contra dispensa discricionária dos dirigentes, os quais terão mandatos por prazo definido e sendo vedada a recondução. Esses fatores possibilitam que as decisões sejam menos afetadas pelo clientelismo e conveniência política com objetivo de continuidade no cargo.

Por fim, um aspecto estrutural, bastante próximo ao funcional, refere-se à natureza material das competências reservadas às agências reguladoras (IV). Esse elemento chama atenção para o fato de que algumas competências normativas não podem ser delegadas às agências reguladoras, uma vez que se relacionam à ideia de escolha do povo, manifestada pelos representantes do povo democraticamente eleitos. Nesse sentido, o poder decisório das agências é limitado e condicionado, reservando-se ao parlamento e ao governo as competências essenciais à configuração do Estado Democrático.

Importa ressaltar que as escolhas de natureza técnico-científica envolvem decisões políticas relacionadas à conveniência e à oportunidade, uma vez que toda escolha requer considerações sobre o contexto em que se aplica. Ainda que a natureza das decisões das agências se paute em critérios científicos, essa característica não isenta a responsabilidade de assegurar instrumentos democráticos internos.

Desse modo, é incorreto afirmar que a legitimação das agências não se faz pela via democrática, mas por meio da eficiência de sua atuação. Nesse sentido, a observância aos elementos estruturais deve ser acompanhada à dos elementos funcionais que possibilitam aferir os índices democráticos da regulação independente.

Os elementos funcionais caracterizadores do déficit democrático interno relacionam-se ao exercício das competências atribuídas às agências. Além da organização estrutural, elementos funcionais devem ser verificados na atuação das agências, a fim de que se assegure a participação social de forma ampla, garantindo-se princípios e valores fundamentais (JUSTEN FILHO, 2006, p. 317-321).

Os elementos funcionais podem ser sistematizados em quatro grupos principais de análise. Eles dizem respeito à (I) fundamentação racional técnico-científica das decisões; (II) ao devido processo administrativo; (III) à participação social e (IV) ao controle externo.

No tange ao primeiro grupo, tem-se que as decisões não devem ser subjetivas, autoritárias ou arbitrárias (I). No processo de tomada de decisão, deve-se evitar qualquer atuação que se paute apenas na vontade da autoridade administrativa de maior hierarquia, baseada na conveniência ou oportunidade da Administração Pública. A fundamentação técnica das decisões fortalece a 
independência entre os poderes e prima pela tomada de decisão com base no saber técnicocientífico, uma vez que um dos fatores que legitimam a atuação das agências é, justamente, a sua natureza preponderantemente cognitiva.

Outro fator de importante monta para se assegurar manifestações democráticas no âmbito regulatório é o devido processo administrativo (II). Contudo, a legitimação democrática não se configura apenas pela mera existência de um procedimento administrativo, que é um elemento essencial para o desempenho da atividade administrativa.

O processo administrativo, ainda que institucionalizado por uma perspectiva estatal, deve propiciar a abertura suficiente para que seja verificada a viabilidade desse procedimento em relação ao contexto para o qual é aplicado, a partir de uma perspectiva reflexiva e dialógica do Estado Regulador. Desse modo, o procedimento deve oportunizar a participação do particular, de acordo com o contexto fático em que se encontra e com a sua capacidade de manifestação da vontade, sob pena deque os procedimentos adotados pela própria agência sejam inadequados para os fins que se prestam.

O processo administrativo deverá, ainda, conduzir à limitação do poder e à formação de decisões compatíveis com a ordem jurídica e a racionalidade científica. Nesse sentido, o procedimento não é uma mera formalidade a ser observada, mas sim o instrumento útil para a participação de terceiros no processo de tomada de decisão, o que se associa ao terceiro grupo de análise: a participação social (III).

As agências devem atuar como mediadoras de manifestação da vontade popular. No que diz respeito à participação, especial atenção deve ser despendida em questões de natureza técnicocientífica complexa, para que se evite a assimetria de informação entre os participantes e falsas compreensões que acarretem escolhas populares equivocadas. Além disso, a agência deve adotar uma postura de provocação, em busca de uma maior participação dos particulares, bem como para articular os setores especializados não governamentais e demais organizações eventualmente interessadas.

Um dos fatores principais relacionados à participação é o de que ela deve ser relevante para a tomada de decisão. Essa postura demanda que a participação popular seja incorporada no processo decisório, de modo que a sua expressão seja acolhida ou refutada com base em fundamentados técnico-científicos.

Por fim, o último grupo se refere ao controle externo da atuação reguladora (IV). O poder normativo regulador também é limitado por outras esferas de poder, como o executivo, o legislativo e o judiciário, o que evita o abuso das competências próprias e privativas das agências. Por exemplo, o poder executivo acompanha o desempenho e a conduta dos reguladores, inclusive 
para o fim de instalar procedimento de natureza punitiva, já o poder judiciário revisa os atos gerais ou abstratos que possam ser ilegais ou abusivos, em especial os relacionados a direitos coletivos e difusos.

A sistematização dos elementos estruturais e funcionais que caracterizam o déficit democrático interno serve de baliza para que se possa aferir o índice democrático da regulação independente em diferentes setores. No entanto, seria demasiadamente pretencioso, para os fins de um artigo, analisar toda a questão do déficit democrático na regulação hídrica. Desse modo, o propósito deste estudo é a análise do alcance democrático especificamente no que se refere aos comitês de bacia hidrográfica em relação a atuações que se mostram presentes nos mais expressivos casos de conflitos hídrico nacionais, a criação de CBHs na região do baixo amazonas e a função de primeira instância para a resolução de conflitos.

\section{O ALCANCE DEMOCRÁTICO DOS COMITÊS DE BACIA HIDROGRÁFICA COMO MECANISMOS DE PARTICIPAÇÃO E DE GESTÃO COMPARTILHADA DOS RECURSOS HÍDRICOS}

O regime geral de águas no Brasil é caracterizado por um processo decisório de responsabilidades compartilhadas, segundo um modelo institucional descentralizado e participativo, entre os entes que compõem o Sistema Nacional de Gerenciamento de Recursos Hídricos, de acordo com a Política Nacional de Recursos Hídricos (FERRAÇO, 2019). Os Comitês de Bacia Hidrográfica, um dos entes do SINGREH, desempenha um papel de destaque na gestão compartilhada dos recursos hídricos, na medida em que é o âmbito de decisão mais próximo à unidade de gestão, bem como pelo seu caráter participativo e democrático de mediação entre o poder público e os particulares (art. 33, inciso III, da PNRH).

Os CBH's foram instituídos como o âmbito de promoção ao debate sobre questões hídricas e de articulação para a participação de representantes de diferentes segmentos interessados na gestão do recurso, como o de energia e irrigação, por exemplo. A partir dessa proposta de abertura participativa, as principais atribuições dos comitês são as de aprovar o Plano de Recursos Hídricos da bacia e a de arbitrar, em primeira instância administrativa, os conflitos relacionados aos recursos hídricos (artigo 38, incisos I a IX, da PNRH).

A criação dos CBH's encontra motivação, portanto, na ocorrência de conflitos hídricos em razão da diversidade de interesses para o uso do recurso. Nesse sentido, uma primeira via para a solução de eventuais conflitos, tal como esculpido pela PNRH, é pela construção coletiva sobre as prioridades de usos para os recursos disponíveis na bacia hidrográfica (SILVA, 2018). Os comitês 
são, especificamente, o primeiro âmbito administrativo em que é possível alcançar a solução de eventuais conflitos com abertura participativa dos poderes públicos, dos usuários e da sociedade civil envolvidos na gestão dos recursos a partir de um ambiente deliberativo (art. 38, inciso II, da PNRH).

Nesse contexto, os comitês materializam a descentralização político-administrativa da gestão da água, constituindo arenas jurídico legais de compartilhamento de interesses de diferentes segmentos da sociedade civil organizada e de responsabilidades entre as estruturas governamentais em seus três níveis - nacional, estadual, municipal (FERRI; et al, 2017). A participação para a tomada de decisões de medidas de gestão é um processo complexo, que requer maturidade política e institucional-democrática para o envolvimento da sociedade (YOUNG, et. al., 2018).

Além disso, uma das atribuições mais relevantes dos Comitês é a de aprovar o Plano de Recursos Hídricos da bacia hidrográfica (art. 38, inciso III, da PNRH). O plano de bacia hidrográfica é o instrumento que estabelece diretrizes, metas, medidas de racionalização, critérios de cobrança e as prioridades para a outorga dos usos da água, respeitadas as prioridades legais, com base nos dados técnicos hidrológicos, bem como pela consideração dos membros dos comitês. Nesse instrumento, tem-se a oportunidade de materializar a decisão popular, por meio da abertura proporcionada pelos princípios da participação e da descentralização da PNRH (BRASIL, 2015).

Estudos anteriores demonstram, por uma perspectiva estrutural e institucional, que organização dos CBH's favorece a implementação de uma regulação dos recursos hídricos voltada ao interesse público, com base da participação popular, ainda que esses mecanismos comportem algum grau de aperfeiçoamento (SILVA, 2018). Nesse sentido, pode-se afirmar que, por uma perspectiva estrutural, os comitês de bacia hidrográfica não apresentariam um déficit democrático. No entanto, para que essa afirmação se sustente, deve-se pressupor a existência de comitês em todas as unidades de gestão, o que não ocorre no Brasil.

Diante disso, resta questionar se a atuação dos CBH's, a partir da sua instalação e desempenho das principais atribuições, apresenta algum grau de déficit democrático. Para que seja possível realizar esse percurso investigativo, o presente estudo se apropria de casos de conflitos hídricos que se relacionem à aprovação de prioridades de uso pelos comitês de bacia hidrográfica e à resolução de conflitos hídricos de abrangência nacional, uma vez que esse âmbito possibilita analisar a descentralização da gestão em relação aos entes do SINGREH, bem como nos casos de instalação dos CBH's no Brasil.

Nesse interim, tendo-se em conta que os Comitês de Bacia Hidrográfica foram idealizados como mecanismos de abertura popular para a gestão compartilhada e democrática dos recursos hídricos, pode-se perquirir em que medida a função desempenhada por eles é capaz de suprir o 
déficit democrático no setor hídrico. A fim de que tal investigação seja possível, serão utilizados os elementos sistematizados na primeira parte deste artigo, sendo que a caraterização dos elementos funcionais ocorre pelos fatores de (I) fundamentação racional técnico-científica das decisões; (II) o devido processo administrativo; (III) a participação social e (IV) o controle externo; e a caracterização elementos estruturais ocorre pelos fatores de (I) composição colegiada com competências compartilhadas, (II) da disciplina sobre a escolha dos membros, (III) da situação jurídica dos dirigentes das agências e (IV) da competência regulatória.

Importa destacar que a sistematização dos elementos configuradores do déficit democrático interno da regulação independente serve de amparo para a aferição deste índice em toda a organização setorial hídrica, bem como de todas as atribuições dos $\mathrm{CBH}$ 's. No entanto, a análise do referido déficit em todos os níveis da regulação hídrica, para os fins de um artigo, seria demasiadamente pretenciosa. Nesse sentido, a análise das funções dos comitês realizada neste estudo ocorre em razão de dois elementos intimamente relacionados à regulação hídrica: a exploração do potencial hídrico, no caso das bacias hidrográficas Amazônica e do Tocantins Araguaia; assim como pelo grau de envolvimento das instituições públicas do executivo e do judiciário, no caso da bacia do Rio Paraíba do Sul.

Para cumprir essa investigação, primeiramente, analisa-se a existência do referido déficit no que diz respeito à criação dos comitês em um país de dimensões continentais como o Brasil e a respectiva atribuição de elaboração e aprovação dos planos de bacia hidrográfica (2.1) e, em seguida, verifica-se o índice democrático dos $\mathrm{CBH}$ 's na atuação de primeira instancia administrativa para a resolução de conflitos hídricos (2.2). Por fim, apresentam-se algumas considerações quanto ao déficit democrático nos comitês de bacia hidrográfica como instrumentos de participação da gestão hídrica (2.3).

\subsection{O déficit democrático na instalação dos Comitês de Bacia Hidrográfica no Brasil}

A instalação dos Comitês de Bacia Hidrográfica em um país com dimensões continentais e a respectiva aprovação do plano de bacia não ocorrem de maneira uniforme. No Brasil, existe uma concentração de tais entidades nas regiões metropolitanas, sobretudo nos estados litorâneos do nordeste, sudeste e sul do Brasil (ANA, 2019).

Essa disparidade indica uma preponderância dos mecanismos de participação em zonas de maior desenvolvimento urbano ou em locais em que a questão hídrica, em razão da sua escassez, é um interesse público. Por outro lado, em regiões em que a água se encontra em nível quantitativo de qualitativo abundantes, a exemplo da Amazônica, a instalação dos CBH's ocorre de forma 
bastante tímida.

Devido à existência de poucos CBH's instalados no Brasil, uma via para a edição dos planos de bacia tem sido a elaboração por meio das entidades ou órgãos gestores de recursos hídricos e sua respectiva aprovação pelos comitês a serem instalados futuramente (BRASIL, 2015, p. 46). Se, por um lado, tem-se a necessidade de edição dos planos para que seja possível estabelecer os critérios de prioridade para a concessão de outorga de uso, que possibilita a expansão das atividades dos setores alimentício e energético, economicamente estratégicos para a região e para a União, por outro, tem-se um óbice à participação democrática, uma vez que a elaboração desses instrumentos por entidades ou órgãos federais não abre espaço para a consideração dos interesses dos diretamente afetados pela utilização do recurso.

Uma importante área para a análise dessa questão, reconhecida como o berço de uma grande biodiversidade e também com ótimo potencial hidrelétrico, é a região Amazônica. Essa região abrange a Bacia Amazônica e a Bacia Tocantins Araguaia, que juntas dispõem de 53\% do potencial hidrelétrico do Brasil (BRASIL, 2008, p. 36), mas também contam com áreas de preservação ambiental e comunidades tradicionais instaladas ao redor das bacias.

Com o início das medidas para a exploração do potencial energético da região, foram ajuizadas dez ações civis públicas pelo Ministério Público Federal - MPF para que a ANA seja proibida de emitir a Declaração de Reserva de Disponibilidade Hídrica - DRDH. A principal questão levantada pelo MPF nas ações civis públicas é a ausência de Comitês de Bacia Hidrográficas instalados nas bacias da região, sem as quais não há aprovação do Plano de Recursos Hídricos que estabelece as prioridades dos usos dos recursos hídricos. Esse fato, inclusive, foi reconhecido pelo Conselho Nacional de Recursos Hídricos na resolução n 128 de 2011, ao afirmar que "ainda não foi instituído Comitê da Bacia Hidrográfica em nenhum dos afluentes da área da margem direita do rio Amazonas” (BRASIL, 2011).

Devido à inexistência de CBH's instalados, a concessão de DRDH resta prejudicada, assim como a sua conversão na declaração em outorga de uso, uma vez que as prioridades de uso da unidade de gestão ainda não foram estipuladas e reguladas pelos respectivos comitês.

Como uma alternativa para a ausência de CBH's instalados em alguns afluentes, o CNRH aprovou, em 2011, o Plano Estratégico de Recursos Hídricos dos Afluentes da Margem Direita do Rio Amazonas (PERH-MDA), com o objetivo de suprir a inexistência dos planos para a região. Três anos após a aprovação do plano, a ANA informou não dispor de um acompanhamento sistemático da implementação do PERH-MAD, ressaltando que, nos termos da PNRH, caberia ao CBH o acompanhamento da execução do plano da bacia, assim como para emitir sugestões das providências necessárias ao cumprimento de suas metas. Não obstante, a agência nacional realizava 
a emissão de DRDH, que posteriormente eram convertidas em outorgas para o funcionamento de usinas hidrelétricas na região.

Em sua defesa, a Agência Nacional de Águas sustenta a ausência de responsabilidade no que tange à implantação dos comitês, alegando se tratar de uma competência direta da União e não do órgão federal regulador. Além disso, a ANA defende que a PNRH não impõe como condição para emissão de Outorgas a existência de CBH's instalados, pois, se assim o fosse, estaria configurado um grande empecilho para o aproveitamento econômico do potencial hídrico nacional.

No que tange à análise de déficit democrático dessa questão, pode-se afirmar que a elaboração dos planos de bacia por outras entidades, que não o $\mathrm{CBH}$ da unidade de gestão, viola alguns dos elementos caracterizadores do prisma funcional e estrutural do déficit democrático interno.

Primeiro, pode-se apontar uma violação funcional ao processo administrativo e estrutural à competência regulatória, uma vez que há uma usurpação da competência definida pela PNRH para a aprovação dos planos de bacia hidrográfica pelos comitês, bem como a alteração dos limites das unidades de gestão. De acordo com a lei, deve haver um plano para cada bacia hidrográfica (art. $\left.8^{\circ}, \mathrm{PNRH}\right)$, o qual deverá ser aprovado pelo respectivo comitê que abrange a bacia hidrográfica (art. 38, III, PNRH).

Segundo, há uma violação funcional ao controle externo no processo de tomada de decisão, na medida em que as prioridades não são eleitas conforme os interesses dos representantes dos CBH's, mas por outros atores públicos. A medida esvazia a autonomia decisória dos comitês, tendo em vista a resistência representada pela administração pública em compartilhar efetivamente o poder com as instâncias descentralizadas e participativas (BRASIL, 2015, p. 49).

Terceiro, há uma clara violação funcional à participação social. A elaboração de planos diante da ausência de comitês de bacia viola o fundamento da gestão descentralizada dos recursos hídricos (art. $\left.1^{\circ}, \mathrm{VI}, \mathrm{PNRH}\right)$ e as diretrizes de articulação e adequação entre os entes federativos, em função das diversidades regionais (art.2 ${ }^{\circ}$, II e IV, PNRH). Essa questão enfrenta uma complexidade inerente à forma federativa de organização estatal, tanto administrativa quanto legislativa (OLIVEIRA, 2012), e a sua adequação aos princípios de um Estado Democrático de Direito (COSTA, 2013).

A participação multinível de gestão proposta pela PNRH tem, por base, os CBH's e, no ápice, a Agência Nacional de Águas e o Conselho Nacional de Recursos Hídricos. Descentralizar, nos termos propostos pela política, significa que o poder público não administrará os recursos hídricos diretamente, ocorrendo a transferência de atribuições ou poderes tradicionais da União e 
dos Estados para os atores que compõe o SIGREH. Nesse sentido, a medida adotada pela agência e pelo conselho apresentam baixo índice democrático funcional, sobretudo ao se ter em conta que a medida se sobrepõe a uma das principais funções dos CBH's, os quais foram idealizados com o intuito de viabilizar a participação social.

Por fim, há uma violação estrutural no que se refere à própria composição dos tomadores de decisão. A gestão participativa e descentralizada é reforçada pelo art. $39, \$ 1^{\circ}$ da $\mathrm{PNRH}$, pois o poder público não detém a maioria dos votos nos Comitês de Bacia, elemento que possibilita maior controle e participação social na tomada de decisões (MACHADO, 2018, p. 24).

Nesse sentido, os CBH's são compostos por representantes não apenas do poder público federal, mas também pelo poder público estadual, por usuários das águas de sua área de atuação e das entidades civis de recursos hídricos com atuação comprovada na bacia (art. 39, PNRH). Desse modo, a elaboração centralizada e unilateral do Plano de Recursos Hídricos em âmbito federal esvazia a participação democrática local, assim como o controle e a participação social na tomada de decisão (AMARAL e CARVALHO, 2018).

\subsection{O déficit democrático funcional dos Comitês de Bacia Hidrográfica na função de primeira instância administrativa para a resolução de conflitos hídricos}

Os Comitês de Bacia Hidrográfica representam um importante espaço para a resolução de conflitos em torno do uso da água. Por se tratar de um ente colegiado, os CBH's possuem atribuições normativas, deliberativas e consultivas, sendo o âmbito responsável por arbitrar administrativamente, em primeira instância, os conflitos hídricos que abarquem sua área de atuação, segundo dispõe o art. 38, II, da PNRH.

Essa configuração quanto à resolução de conflitos pelos CBH's almeja tornar mais democrático e participativo o poder decisório no processo de gestão integrada. Essa nova alocação implica na redução de custos de transação, uma vez pretende tornar mais eficiente o aproveitamento de informações quanto às demandas, tendo em vista a maior capacidade de adaptação às necessidades e aos interesses locais (MESQUITA, 2018. p. 57).

No entanto, o caso da disputa hídrica entre Rio de Janeiro e São Paulo pelo uso das águas do Rio Paraíba do Sul, no contexto da crise hídrica que assolou o sistema da Cantareira em 2014, demonstra que essa atribuição apresenta falhas em termos de eficiência e participação democrática. O conflito se configurou a partir da crise hídrica na região sudestes de 2013 e 2014, com o anúncio de que o estado de São Paulo realizaria a transposição de águas entre o Rio Jaguari, importante afluente do Rio Paraíba do Sul, para o Sistema Altibainha-Cantareira. Essa medida enfrentou forte 
resistência do governo do Rio de Janeiro, uma vez que o rio Paraíba do Sul é a principal fonte captação de água do estado e a redução do volume de água à montante afetaria a qualidade da água fornecida para a região fluminense (OROSCO, 2018).

A bacia hidrográfica do Rio Paraíba do Sul é palco de interesses associados à atividade industrial dos estados de São Paulo e Rio de Janeiro, bem como para a geração de energia hidrelétrica na região e abastecimento humano (RIBEIRO et. al, 2008). Considerando o conflito de interesse, a ANA e os estados realizaram um acordo que resultou na edição da Resolução $n^{\circ}$ 1309 de 2014, que autorizou a redução de vazão do volume do rio a partir de setembro de 2014 e pediu a decretação de estado de calamidade pública na região banhada pelo Paraíba do Sul pelos dois anos seguintes.

No entanto, o MPF do Rio de Janeiro alegou que a resolução era um artifício para que o estado de São Paulo pudesse desviar a água do rio, sem passar por um procedimento legal e pelos estudos técnicos de viabilidade. A grande problemática residia na possibilidade de a transposição das águas suprir o abastecimento da população paulista, mas reduzir o quantitativo que abastece a população carioca. A medida, portanto, originaria outro problema de abastecimento ao tentar solucionar a situação paulista.

A partir disso, o MPF ajuizou duas ações civis públicas alegando a possibilidade de risco ao meio ambiente pela realização das obras, bem como sustentou que a transposição do rio afetaria a saúde das populações por ele abastecidas. Requereu, em caráter liminar, que a ANA não autorizasse a realização da obra até que os estudos ambientais fossem realizados pelo IBAMA. A ação, que foi ajuizada na justiça federal do Rio de Janeiro, teve sua competência declinada em face da competência originaria do Supremo Tribunal Federal - STF para julgar a demanda, tendo em conta a necessidade de manutenção do equilíbrio entre os entes da federação, nos termos do art. 102 da Constituição Brasileira.

O pedido liminar foi negado pelo STF por considerar ausentes os dados técnicos suficientes para uma conclusão definitiva dos efeitos de uma eventual transposição do Rio Paraíba do Sul com o objetivo de suprir o sistema Cantareira. A Suprema Corte ressaltou que o equacionamento para esse tipo de questão requer um diálogo propositivo entre os estados diretamente afetados, tendo em conta que todos compartilham o objetivo de fornecer água para as suas populações. No entanto, ainda que a medida apresentasse algum grau de articulação institucional, ela excluía a participação de todos os membros da sociedade, concentrando-se apenas no poder executivo e delegando a solução ao judiciário.

O direcionamento do STF para a composição entre os estados levou à tentativa de um acordo, em 2015, para solucionar o conflito. O acordo teve efeitos em ambas as ações civis ao 
estabelecer as condições de operação do Sistema Hidráulico Paraíba do Sul, compreendendo os reservatórios então instalados na bacia, bem como referendou a viabilidade hidrológica da transposição das águas da bacia para o Sistema Cantareira, em São Paulo.

Contudo, o acordo celebrado não foi capaz de dirimir o conflito. Em 2017, a ProcuradoriaGeral da República suscitou a falta de convergência entre os entes envolvidos acerca das questões que não foram objeto do acordo anteriormente formado. O Supremo Tribunal Federal, após as diversas tentativas de resolução consensual, remeteu as ações à instância originária da Justiça Federal da região por entender que o conflito não apresenta lesividade ao pacto federativo.

O deslinde do caso da disputa hídrica entre Rio de Janeiro e São Paulo pelas águas do rio Paraíba do Sul, demonstra que a atribuição dos CBH's como um âmbito para resolução de conflitos ainda não se apresenta de modo consolidado no Brasil. Ainda que o caso tenha apresentado grande repercussão nacional, a proposta de solução esvaziou as atribuições do Comitê, sendo o conflito verticalizado para uma resolução no STF, uma vez que a ANA e o STF editaram a proposta de um acordo entre os envolvidos. Essa atuação contraria o disposto no art. 38, II, da PNRH, na medida em que obsta a busca por uma solução participativa local (FERRAÇO, 2019).

No caso em questão, o esvaziamento da participação democrático na função de primeira instancia administrativa para a resolução de conflitos dos CBH's é bastante perceptível. A análise desse caso possibilita apontar alguns dos elementos caracterizadores do déficit democrático interno, tanto por prisma funcional, quanto por um prisma estrutural.

Num primeiro momento, pode-se afirmar que o devido processo administrativo e a disciplina quanto à competência não foram observados. Esses elementos funcionais e estruturais ficam evidentes a partir da judicialização direta da disputa hídrica, uma vez que não houve qualquer procedimento administrativo com a finalidade de resolução do conflito de forma direta, de modo que a competência do $\mathrm{CBH}$ para a resolução dos conflitos em primeira instância não foi observada.

Nesse sentido, importa ressaltar que a bacia hidrográfica onde se situa o conflito dispõe de Comitê instalado e em atuação, o Comitê Integrado de Bacia Hidrográfica do Paraíba do Sul (CEIVAP). Não obstante, via de resolução do conflito foi a judicial, por uma atuação federalizada, através da mediação do STF em uma resolução conjunta da Ana Nacional de Águas e de órgãos técnicos dos estados de São Paulo, Minas Gerais e Rio de Janeiro.

A via de resolução escolhida desconsidera possíveis medidas mais eficientes do ponto de vista da gestão compartilhada do recurso, de modo que viola, também, a fundamentação racional técnico-científica das decisões e não oportuniza a participação social. A proposta de solução então apresentada não alcançou efeitos satisfatórios, uma vez que a análise das Ações Civis Públicas sobre o caso demonstra a pouca eficiência quanto às medidas adotadas e a irresignação quanto aos 
resultados práticos alcançados.

A violação a estes elementos fica ainda mais clara ao se considerar que, antes da instauração da crise, em 2013, o CEIVAP emitiu uma série de estudos sobre avaliação dos Impactos de Novas Transposições de Vazão no Rio Paraíba do Sul, de acordo com as previsões do Plano Diretor de Aproveitamento de Recursos Hídricos para a Macrometrópole Paulista. O parecer do comitê à época não foi favorável à realização de novas transposições, uma vez que a situação qualitativa e quantitativa já se apresentava sensível, de modo que qualquer alteração na bacia, especialmente em períodos de estiagens mais severas, implicaria em riscos quanto à garantia do uso múltiplo das águas (OROSCO, 2018).

\subsection{O déficit democrático nos Comitês de Bacia Hidrográfica como instrumentos de participação da gestão hídrica}

Diante da análise dos elementos caracterizadores do déficit democrático, seria possível afirmar a existência do um déficit democrático nos Comitês de Bacia Hidrográfica, ainda que a idealização desses mecanismos encontre fundamento na participação democrática para a gestão dos recursos hídricos? A resposta para essa pergunta, de modo geral, é negativa.

A primeira ressalva a esta questão é a de que seria equivocado generalizar a atuação dos CBH's como mecanismos falhos do ponto de vista democrático de viés participativo. Pode-se afirmar, no entanto, que o sistema político brasileiro, como um todo, ainda não atingiu um estágio de desenvolvimento democrático maduro e estável, sobretudo no que se refere aos mecanismos efetivos de limitação do poder, em especial em relação ao Executivo (JUSTEN FILHO, 2016).

Não obstante, em relação aos CBH's, a atuação desses entes, em especial no que se refere à elaboração dos planos de bacia, ressalta a sistematicidade que os instrumentos propostos pela PNRH para a alocação de recursos hídricos (LACERDA, THOMAS, 2019). Os Planos de Bacia Hidrográfica cristalizam as manifestações da vontade pública envolvida nos processos decisórios no âmbito dos comitês, de modo que estabelecem as diretrizes para aplicação de outros instrumentos de gestão, comportando orientações sobre como proceder à outorga na bacia, por exemplo. Ainda que a atuação dos CBH's não seja capaz de alterar o planejamento setorial hídrico por si só, os Planos de Recursos Hídricos são importantes instrumentos que solidificam a interlocução entre os atores e setores envolvidos, a partir de um ambiente de negociações que propicia a perspectiva de harmonia dos diferentes usos e visões que uma bacia comporta (FERRAÇO, 2019).

Exemplo disso foi a atuação da ANA para a suspensão da concessão de outorgas e 
declarações de reserva de disponibilidade hídrica para empreendimentos hidrelétricos em rios nacionais na Região Hidrográfica do Paraguai, onde se encontra o Pantanal mato-grossense. A medida, que foi implementada por meio da Resolução n 64/2018 da ANA, que tem o objetivo evitar que a construção das barragens para a geração de energia elétrica prejudique os usos múltiplos da bacia, em especial a pesca e o turismo, além de pretender a preservação da Região que abriga um importante bioma brasileiro. A Resolução confere normatividades às disposições do Plano de Recursos Hídricos da região do Paraguai, elaborado pelos governos dos estados de Mato Grosso, Mato Grosso do Sul e pela sociedade civil, que apresenta como uma de suas diretrizes para a outorga a necessidade de aguardar os resultados dos estudos sobre os efeitos socioeconômicos e ambientais da implantação de empreendimentos hidrelétricos, que estão previstos para serem concluídos até 2020 (FERRAÇO, 2019).

Ao conferir normatividade às diretrizes de gestão cristalizadas nos planos de bacia hidrográfica, por meio de suas resoluções normativas, a ANA promove a inclusão social das populações no processo de decisão para a gestão dos recursos hídricos. Essa atuação privilegia uma visão democrática para o uso das águas da região hidrográfica, uma vez que considera a configuração geográfica da formação da bacia e possibilita que as decisões para os usos do recurso comportem outros elementos, além do valor econômico previsto para a água pela legislação brasileira (art. $1^{\circ}$, II da Lei 9.433/97).

Nesse sentido, a participação democrática da população no processo de escolhas das diretrizes para a outorga, a partir da atuação dos comitês, posteriormente inseridas no Plano de Recursos Hídricos, possibilita a satisfação de necessidades observadas diretamente pelas partes interessadas em âmbito local, o que expressa respeito às identidades coletivas e multiplicidade de interesses para os usos dos recursos hídricos.

Por outro ângulo, a resolução dos conflitos no âmbito administrativo dos CBH's apresenta falhas de eficiência. Essa atuação pode ser prejudicada por alguns fatores, tais como a insuficiência de aptidão técnica ou administrativa para deliberar ou executar efetivamente o planejamento hídrico, ou, ainda, quando os interesses políticos locais são caracterizados por clientelismo ou corrupção, o que faz com que as decisões administrativas não observem as prioridades técnicas. Nesse contexto, a participação democrática resta prejudicada, na medida em que o processo decisório cede às pressões dos interesses das elites locais ou quando a sociedade civil local não se apresenta de forma bem organizada (FERRAÇO, 2019).

Ainda que a implementação e aperfeiçoamento dos instrumentos de gestão hídrica tenha apresentado avanços organizacionais e institucionais, as lacunas para uma gestão integrada e participativa, diante das responsabilidades compartilhadas, ainda são muito presentes no contexto 
nacional (THEODORO; NASCIMENTO, 2016). Em uma tentativa de se conferir maior participação popular na gestão hídrica, a Política Nacional de Recursos Hídricos prevê uma gestão descentralizada, participativa e integrada do recurso.

Alcançar a descentralização proposta pela PNRH requer observância à articulação entre os entes que compõem o SINGREH, havendo abertura à participação democrática para a consideração dos interesses locais dos diretamente afetados, com o objetivo de superar os óbices observados pela sobreposição de interesses setorizados na gestão hídrica nacional, bem como na prevalência das medidas verticalizadas da Administração Pública. No que tange aos Comitês de Bacia Hidrográfica, essa medida se inicia com a promoção de uma maior articulação para a interlocução dos interessados em grau de paridade, conforme idealizado pela política nacional em seus fundamentos e diretrizes.

\section{CONCLUSÃO}

A legitimidade democrática das agências reguladoras independentes é questionada pelo fato de que sua normatividade não emana dos representantes elegidos pelo povo, mas por indicados pelo chefe do poder executivo e aprovados pelo legislativo. Nesse sentido, a compatibilidade com o Estado Democrático de Direito e a atividade normativa extraordinária do Poder Executivo, por meio da regulação independente, adquire feições democráticas na medida em que o Estado busca concretizar mecanismos de participação e controle social, tanto políticos quanto jurídicos.

A atuação das agências reguladoras deve viabilizar a participação dos regulados por meio de instrumentos democráticos. Uma vez que essas vias de interlocução democrática apresentem falhas de eficiência para a participação direta do cidadão na formação da vontade política, é possível se falar em um déficit democrático na regulação.

Diante disso, a legitimação regulatória encontra outras vias, que não o critério da eletividade, para a sua configuração democrática. O caráter democrático de uma agência é extraído a partir do aspecto técnico de sua atuação, resguardado pela eficiência da regulação. No âmbito da regulação independente, a legitimação é extraída pela sua atividade técnica. A legitimação técnica das agências reguladoras aperfeiçoa o sistema de freios e contrapesos, assim como amplia as vias de participação entre a sociedade e as instituições públicas. Nesse ínterim, a legitimação técnica é mensurada a partir de parâmetros técnico-científicos, os quais se sujeitam aos princípios constitucionais e à finalidade pública de sua atuação.

A existência das agências reguladoras, portanto, aperfeiçoa o sistema democrático a partir de duas contribuições principais: a de resguardar a realização de direitos fundamentais e a de 
ampliar os canais de comunicação entre a sociedade e o Estado. Nesses moldes, a existência das agências reguladoras supre o a ausência de vias de mediação entre o Estado e os particulares, o que se refere ao déficit democrático externo da regulação, ao passo que essas instituições atenuam a concentração de poder nas mãos do poder executivo originário.

De modo complementar, a atenuação do déficit democrático externo deve ser acompanhada pelo suprimento do déficit democrático interno. Nesse sentido, torna-se necessário analisar a organização regulatória a partir de critérios estruturais de ordem organizacional, bem como pelo desempenho de suas funções, de modo a evidenciar se a atuação da agência é pautada pela garantia do exercício de direitos fundamentais, sobretudo, dando abertura à participação popular processo de tomada de decisões.

A importância da análise funcional e estrutural ganha importância a partir da possibilidade de se pensar na superação do déficit democrático por uma lógica meramente formal. A criação de agências ou estruturas regulatórias com o objetivo de viabilizar manifestações democráticas por um viés meramente instrumental, mas que, de fato, não apresentam contribuições substanciais para o aperfeiçoamento do sistema democrático, não suprem a carência democrática regulatória.

Diante disse, a análise de déficit interno é orientada por elementos estruturais e funcionais. Os elementos estruturais que configuram o déficit democrático interno dizem respeito à (I) composição colegiada com competências compartilhadas, (II) à disciplina sobre a escolha dos membros, (III) à disciplina sobre a situação jurídica dos dirigentes das agências e (IV) à disciplina sobre a competência regulatória. Já os elementos funcionais relacionam-se à (I) fundamentação racional técnico-científica das decisões; (II) ao devido processo administrativo; (III) à participação social e (IV) ao controle externo.

No âmbito da regulação hídrica, um importante mecanismo de participação democrática na tomada de decisão para a gestão dos recursos hídricos são os Comitês de Bacia Hidrográfica. Os CBH's foram instituídos como o âmbito de promoção ao debate sobre questões hídricas e de articulação para a participação de representantes de diferentes segmentos interessados na gestão do recurso. A partir dessa proposta de abertura participativa, as principais atribuições dos comitês são as de aprovar o Plano de Recursos Hídricos da bacia e a de arbitrar, em primeira instância administrativa, os conflitos relacionados aos recursos hídricos.

A partir da constatação do ideal participativo e democrático dos Comitês de Bacia Hidrográfica na gestão compartilhada dos recursos hídricos, torna-se cabível a análise da função por eles desempenhada, a partir dos elementos que caracterizam o déficit democrático, em duas questões relacionadas aos conflitos hídricos nacionais: a instalação de comitês de bacia hidrográfica e a sua atuação como primeira instância administrativa para a resolução de conflitos hídricos. 
A análise dessas questões, a partir de casos envolvendo as bacias hidrográficas Amazônica, Tocantins Araguaia e a do Rio Paraíba do Sul, possibilitam afirmar que a atuação dos comitês requer um aprimoramento em termos estruturais, relacionados às disciplinas de composição dos membros tomadores de decisão, sobre a competência regulatória; e funcionais, atinentes à fundamentação racional técnico-científica das decisões, ao devido processo administrativo, à participação social e ao controle externo.

Ainda que não se possa afirmar a existência de um déficit democrático na regulação hídrica nacional de modo generalizado, certo é que o sistema político brasileiro ainda não atingiu um estágio de desenvolvimento democrático maduro e estável, sobretudo no que se refere aos mecanismos efetivos de limitação do poder, em especial em relação ao Executivo.

No âmbito da regulação hídrica, o aperfeiçoamento organizacional e institucional para uma gestão a descentralizada e participativa requer a articulação entre os entes do Sistema Nacional de Gerenciamento dos Recursos Hídricos, com a devida abertura à participação democrática para a consideração dos interesses locais dos diretamente afetados. A partir dessa perspectiva, torna-se possível superar os óbices observados pela sobreposição de interesses setorizados na gestão hídrica nacional, bem como na prevalência das medidas verticalizadas da Administração Pública.

\section{REFERÊNCIAS BIBLIOGRÁFICAS}

AMARAL, Claudia Tannus Gurgel do; CARVALHO, Francisco Toniolo de. Democracia e deliberação: a escolha popular das políticas públicas locais - o caso do orçamento participativo de porto alegre (OPPOA). Revista de Direito da Cidade, vol. 10, n 1, pp. 463-485, 2018.

ARAGÃO, Alexandre dos Santos. O Atual Estágio de Regulação Estatal. ARAGÃO, Alexandre dos Santos. Agências Reguladoras e a Evolução do Direito Administrativo Econômico. 2 ed. Rio de Janeiro: Forense, 2005.

ARANHA, M. I. Manual de Direito Regulatório. 5. ed. Londres: Laccademia, 2019.

BINENBOJM, Gustavo. Uma Teoria do Direito Administrativo: Direitos Fundamentais, Democracia e Constitucionalização. Rio de Janeiro: Renovar, 2006.

BRASIL. AGÊNCIA NACIONAL DE ÁGUAS - ANA. Bacias e estados com planos de recursos hídricos: mapa interativo. Informações sobre recursos hídricos: Planejamento. 2019.

BRASIL. CONGRESSO NACIONAL. CÂMARA DOS DEPUTADOS. Centro de Estudos e Debates Estratégicos. Instrumentos de gestão das águas [recurso eletrônico] / Câmara dos Deputados, Consultoria Legislativa, Centro de Estudos e Debates Estratégicos; relator Félix Mendonça Júnior; Maurício Boratto Viana, Alberto Pinheiro - Brasília: Câmara dos Deputados, Edições Câmara, 2015.

CROLEY, Steven P. Public interested regulation. Florida State University Law Review. v. 28, 


\section{Revista da Faculdade Mineira de Direito |V.23 N.45|}

2000.

CROLEY, Steven P. Regulation and Public Interests. Princeton: Princeton University Press. 2008.

CROLEY, Steven P. Theories of Regulation: Incorporating the Administrative Process.

Columbia Law Review. v. 98, n. 1. jan. 1998.

COSTA, Luis Alberto. Da autonomia à participação: breves reflexões sobre o federalismo brasileiro na perspectivado constitucionalismo social-dirigente. Revista da Faculdade Mineira de Direito - PUC Minas. Belo Horizonte, v. 16 n. 31, 2013.

DANTAS, Bruno; GOMES, Valdecyr Maciel. A governança nas agências reguladoras: uma proposta para o caso de vacância. Revista de Informação Legislativa: RIL, Brasília, DF, v. 56, n. 222, p. 11-31, abr./jun. 2019.

FERRAÇO, André Augusto Giuriatto. A Insuficiência de Integração na Gestão Nacional dos Recursos Hídricos Brasileiros como Óbice Estrutural ao Desenvolvimento Sustentável. Dissertação - Mestrado em Direito. Universidade de Brasília, 2019.

FIGUEIREDO, Marcelo. As agências reguladoras: o Estado Democrático de Direito no Brasil e sua atividade normativa. São Paulo: Malheiros, 2005.

FERRI, Caroline; et al. CONSELHOS DE POLÍTICAS PÚBLICAS: espaços legítimos de participação social na defesa das políticas públicas. Revista da Faculdade Mineira de Direito PUC Minas. Belo Horizonte, v. 20, n. 39, p. 61-90, out./abr. 2017.

JUSTEN FILHO, Marçal. Agências reguladoras e democracia: existe um déficit democrático na Regulação Independente. ARAGÃO, Eugênio Santos. O poder normativo das agências reguladoras. Rio de Janeiro: Forense, 2006.

LACERDA, N. de M; THOMAS, P. T. Teoria Responsiva da regulação em situações de crises hídricas: uma análise a partir da atuação da Agência Nacional de Águas na crise do Rio Pardo. Revista de Direito Setorial e Regulatório, v. 5, n. 2, p. 1-26, outubro 2019.

MACHADO, Paulo Affonso Leme. Direito de Acesso à Água. São Paulo: Malheiros, 2018.

MARQUES Neto, Floriano de Azevedo. Agências Reguladoras Independentes: fundamentos e seu regime jurídico. Belo Horizonte: Fórum, 2005.

MESQUITA, Luis Fabio Gonçalves. Os comitês de bacias hidrográficas e o gerenciamento integrado na Política Nacional de Recursos Hídricos. Revista Desenvolvimento e Meio Ambiente. pp. 56-80. vol. 45, abril, 2018.

MOURA, K. DE O.; NETO, O. DOS S. S. A superação da tensão existente entre as agências reguladoras brasileiras e o regime democrático. Revista Digital Constituição e Garantia de Direitos, v. 9, n. 2, p. 329 - 349, 19 jun. 2017.

OLIVEIRA, Cláudia Alves de. Competências Ambientais na Federação Brasileira. Revista de Direito da Cidade, vol. 4, n 2, pp. 40-64, 2012. 
ORGANIZAÇÃO PARA A COOPERAÇÃO E DESENVOLVIMENTO ECONÓMICO OU ECONÔMICO - OCDE. Governança dos Recursos Hídricos no Brasil. Paris: OECD Publishing, 2015.

OROSCO, Rebeca Tricarico. Conflitos na Gestão de Recursos Hídricos no Brasil: O Caso da Interligação Jaguari-Atibainha na Bacia Hidrográfica do Rio Paraíba do Sul. in. III Simpósio de Recursos Hídricos da Bacia do Paraíba do Sul - Universidade de Juiz de Fora. Juiz de Fora, 2018.

PORTO, M. F. A.; PORTO, R. L. L. Gestão de bacias hidrográficas. Revista Estudos

Avançados: Dossiê Água. Instituto de Estudos Avançados da USP. V. 33, nº 63, mai-ago/2008.

RIBEIRO, F.; CRUZ, N.C.; SENE, T.C.A.; MANGIALARDO, V.C. A importância do patrimônio natural: o rio Paraíba do Sul. In: XII Encontro Latino Americano de Iniciação Científica e VIII Encontro Latino Americano de Pós-Graduação. Universidade do Vale do Paraíba, 2008.

RIO, Gisela Pires do. Bacia do Paraíba do Sul: a tomada de uma crise de abastecimento de água Paraíba do Sul. in. Anais do XVII ENANPUR: Desenvolvimento, crise e resistência: quais os caminhos do planejamento urbano e regional? São Paulo, 2017.

RUAS, C. A insuficiência da estruturação da independência orgânica das agências reguladoras federais contra a interferência político-partidária. Revista de Direito Setorial e Regulatório, v. 5, n. 1, p. 115-130, 5 maio 2019.

SILVA, A. C. M. da. Participação na gestão dos recursos hídricos como estratégia para uma regulação de interesse público: uma análise dos Comitês de Bacia Hidrográfica a partir da teoria processual administrativa da regulação. Revista de Direito Setorial e Regulatório, Brasília, v. 4, n. 2, p. 19-40, outubro 2018.

SUNDFELD, Carlos Ari. Introdução às Agências Reguladoras. SUNDFELD, Carlos Ari. Direito Administrativo Econômico. São Paulo: Malheiros, 2002.

THEODORO, H. D.; NASCIMENTO, N. O.; Heller, L. Análise comparativa da gestão institucional de recursos hídricos via estudo de casos internacionais. Revista de Gestão de Água da América Latina - REGA, v.13, n. 2, p.110-128, 2016.

YOUNG, Juliana; SERDOURA, Francisco Manuel Serdoura; CRUZ, Jussara Cabral Cruz. Participatory river restoration projects: a tool for better water management. Revista de Direito da Cidade, vol. 10, n. 1, pp. 288-309, 2018.

\section{REFERÊNCIAS NORMATIVAS}

BRASIL. Constituição da República Federativa do Brasil. Promulgada em 5 de outubro de 1988.

BRASIL. Lei nº 9433 de 08 de janeiro de 1997. Política Nacional de Recursos Hídricos.

BRASIL. AGÊNCIA NACIONAL DE ÁGUAS - ANA. Resolução nº $\mathbf{6 8 3}$ de $\mathbf{0 5}$ de maio de 2014. 
BRASIL. AGÊNCIA NACIONAL DE ÁGUAS - ANA. Resolução no $\mathbf{6 4}$, de 04 de Setembro de 2018 - Documento no 00000.054763/2018-16.

BRASIL. MINISTÉRIO DE MEIO AMBIENTE - MMA. CONSELHO NACIONAL DE RECURSOS HÍDRICOS - CNRH. Resolução nº 128, de 29 de junho de 2011.

COMITÊ DA BACIA HIDROGRÁFICA DO RIO PARANAÍBA. DELIBERAÇÃO No 88/2018 de 27 de março de 2018. Aprova as diretrizes para regulação de usos na bacia do rio São Marcos.

\section{REFERÊNCIAS JURISPRUDENCIAIS}

BRASIL. SUPREMO TRIBUNAL FEDERAL - STF. AÇÃO CÍVEL ORIGINÁRIA 2.536 RIO DE JANEIRO. Min. Rel. Luiz Fux. 27.11.2014.

BRASIL. SUPREMO TRIBUNAL FEDERAL - STF. AÇÃO CÍVEL ORIGINÁRIA 2.550 RIO DE JANEIRO. Min. Rel. Luiz Fux. 10.12.2015.

BRASIL. MINISTÉRIO PÚBLICO FEDERAL. Ação Civil Pública nº 000039979.2014.4.01.3102, Tribunal Regional Federal 1 Região, 2019.

BRASIL. MINISTÉRIO PÚBLICO FEDERAL. Ação Civil Pública nº 000147896.2014.4.01.3101; Tribunal Regional Federal 1 Região, 2019.

BRASIL. MINISTÉRIO PÚBLICO FEDERAL. Ação Civil Pública nº 000379067.2014.4.01.3902; Tribunal Regional Federal $1^{\circ}$ Região, 2019.

BRASIL. MINISTÉRIO PÚBLICO FEDERAL. Ação Civil Pública nº 000636539.2014.4.01.3905; Tribunal Regional Federal 1 Região, 2019.

BRASIL. MINISTÉRIO PÚBLICO FEDERAL. Ação Civil Pública nº 000997685.2014.4.01.4200, $1^{a}$ Vara Boa Vista - RR; Tribunal Regional Federal $1^{\circ}$ Região, 2019.

BRASIL. MINISTÉRIO PÚBLICO FEDERAL. Ação Civil Pública nº: 001507545.2014.4.01.4100, $5^{a}$ Vara Porto Velho - RO; Tribunal Regional Federal $1^{\circ}$ Região, 2019.

BRASIL. MINISTÉRIO PÚBLICO FEDERAL. Ação Civil Pública nº 001639869.2014.4.01.3200, $7^{\mathrm{a}}$ Vara Federal Manaus - AM; Tribunal Regional Federal $1^{\circ}$ Região, 2019.

BRASIL. MINISTÉRIO PÚBLICO FEDERAL. Ação Civil Pública n: 001639954.2014.4.01.3200, Tribunal Regional Federal $1^{\circ}$ Região, 2019.

BRASIL. MINISTÉRIO PÚBLICO FEDERAL. Ação Civil Pública n: 001896622.2014.4.01.3600; Tribunal Regional Federal 1 Região, 2019.

BRASIL. MINISTÉRIO PÚBLICO FEDERAL. Ação Civil Pública nº 005035524.2015.4.01.0000; Tribunal Regional Federal 1 Região, 2019. 